
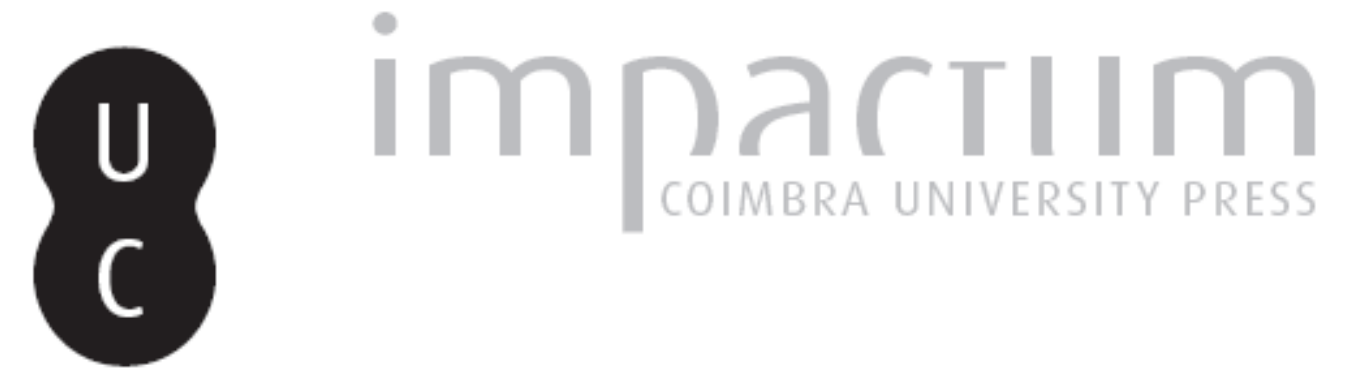

[Recensão a] A Farmácia no mundo pré-clássico e nas culturas tradicionais

Autor(es): $\quad$ Carreira, José Nunes

Publicado por: Faculdade de Letras da Universidade de Coimbra

URL persistente:

URI:http://hdl.handle.net/10316.2/32774

DOI:

DOI:http://dx.doi.org/10.14195/0870-4112_7_26

Accessed : $\quad$ 26-Apr-2023 13:33:03

A navegação consulta e descarregamento dos títulos inseridos nas Bibliotecas Digitais UC Digitalis, UC Pombalina e UC Impactum, pressupõem a aceitação plena e sem reservas dos Termos e Condições de Uso destas Bibliotecas Digitais, disponíveis em https://digitalis.uc.pt/pt-pt/termos.

Conforme exposto nos referidos Termos e Condições de Uso, o descarregamento de títulos de acesso restrito requer uma licença válida de autorização devendo o utilizador aceder ao(s) documento(s) a partir de um endereço de IP da instituição detentora da supramencionada licença.

Ao utilizador é apenas permitido o descarregamento para uso pessoal, pelo que o emprego do(s) título(s) descarregado(s) para outro fim, designadamente comercial, carece de autorização do respetivo autor ou editor da obra.

Na medida em que todas as obras da UC Digitalis se encontram protegidas pelo Código do Direito de Autor e Direitos Conexos e demais legislação aplicável, toda a cópia, parcial ou total, deste documento, nos casos em que é legalmente admitida, deverá conter ou fazer-se acompanhar por este aviso. 


\section{Sociedade em Tumulto}

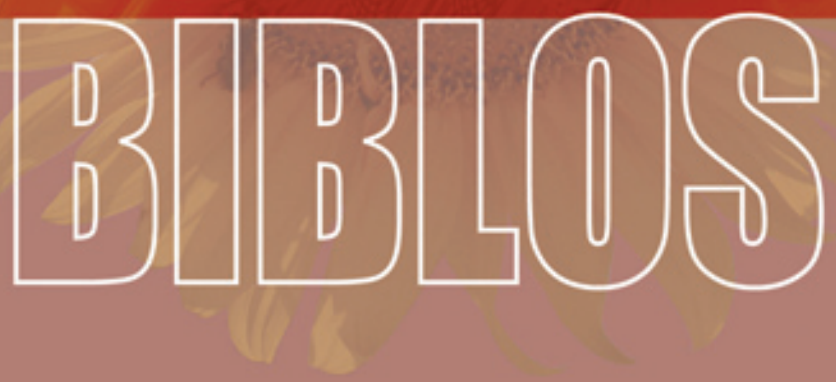

REVISTA DA FACULDADE DE LETRAS

UNIVERSIDADE DE GOIMBRA 
José Nunes Carreira

Universidade de Lisboa

\title{
A FARMÁCIA NO MUNDO PRÉ-CLÁSSICO E NAS CULTURAS TRADICIONAIS
}

\author{
Paula Basso - Luís Manuel de Araújo, Lisboa, \\ Associação Nacional das Farmácias - Museu da Farmácia, \\ 2008 ISBN 282 232/08
}

Em 1996, o Museu da Farmácia «iniciou uma nova fase de expansão da sua colecção, desta vez dedicada à história da farmácia universal» . Nesta perspectiva se elaborou o presente catálogo, evocando «as práticas e os conceitos medicinais das notáveis civilizações que floresceram na Antiguidade Pré-clássica, com um justificado relevo para o Próximo Oriente (Mesopotâmia e regiões vizinhas) e o antigo Egipto» (João Neto, Director do Museu da Farmácia, na «Introdução»). Coube a Paula Basso e Luís Manuel de Araújo a tarefa de seleccionar e descrever as peças, depois de as situarem em esclarecedores textos introdutórios. Boa escolha de dois autores altamente credenciados: a primeira, além de responsável pelo projecto de museologia do Museu, tem escrito sobre farmácia e medicamento (Farmácia Portuguesa, I, Lisboa 2000, Tesouros do Museu da Farmácia, Lisboa 2001, A Farmácia e o Medicamento, Lisboa 2004); o segundo é professor de História e Cultura Pré-clássica, Introdução à Egiptologia e Escrita Hieroglífica, Egípcio Clássico e História da Arte Pré-clássica na Faculdade de Letras da Universidade de Lisboa, e autor de estudos teóricos (nomeadamente Estatuetas funerárias egípcias da XXI dinastia, Lisboa 2003, tese de doutoramento) e catálogos (com destaque para o do Museu Nacional de Arqueologia, Antiguidades Egípcias, I, Lisboa 1993 e o do Museu Gulbenkian, Arte Egípcia. Colecção Calouste Gulbenkian, Lisboa, 2006, com versão inglesa).

A Obra enceta com «A origem da vida e da doença» (pp. 9-13), afirmando programaticamente que «antes de existirem seres humanos na Terra, já existia a doença», perspectiva algo sombria se não se se- 
guisse todo um programa de detecção e combate às maleitas que atormentam o ser humano neste mundo. Deixemos os milhões de anos de evolução das eras geológicas, o aparecimento dos primeiros hominídeos no Pliocénico (de 5,3 a 1,6 milhões de anos), a evolução e dispersão da espécie humana a partir do Pleistocénico (pp. 12-13). Entramos n' «A saúde nos primórdios da humanidade» (pp. 15-19), do início do lento processo da hominização ( «há cerca de 4 ou até 5 milhões de anos, em África», pp. 15-16) ao Neolítico.

«Os primeiros recipientes» (pp. 23-33), feitos de cerâmica («desde o Paleolítico, há cerca de 30000 a. C.», p. 24) e mais tarde de vidro (para alguns inventado «em 3000 a. C. no Egipto», p. 30), levam directamente ao vale do Nilo e à Mesopotâmia pré-históricos e históricos. Do Próximo Oriente provêm, aliás, todas as imagens que ilustram a exposição teórica. A cerâmica está representada com potes de Nippur e vasos egípcios de Deir Tasa, Merimde e Badari. Vê-se a mão de Luís Manuel de Araújo, aliás justamente citado, remetendo para exemplares de museus e colecções privadas portugueses - «sugestivos exemplos de cerâmica pré-dinástica» (p. 27) - e para o catálogo do museu da Farmácia (passim). No século XVI a. C., o progresso tecnológico «conduziu à criação dos primeiros vasos de vidro e deu origem à indústria vidreira» (p. 31), primeiro na Mesopotâmia e depois no Egipto.

«A saúde nas civilizações pré-clássicas» ocupa merecidamente a parte de leão (pp. 35-123) pelo número e qualidade de produções. Começa-se pela Mesopotâmia, subdividida (p. 36) em Suméria (40002000 a. C.), Babilónia (2000-1350), Assíria (1350-612) e Caldeia (612539). «Mais do que às capacidades dos médicos recorria-se à protecção divina» (p. 37), com crenças «em eficazes divindades protectoras», nomeadamente Ea, Inanna-Ishtar, Shamash (Chamach) e Marduk. Demónios malévolos também não faltavam, mas contra eles havia sacerdotes especializados, munidos de um arsenal de exorcismos. Examinava-se o fígado de animais imolados para fins de adivinhação (hepatoscopia). Enumeram-se os três tipos de sacerdotes: baru (vidente), ashipu (achipu, exorcista) e asu (médico). E não se ficava por rezas e superstições. Recorria-se a «dezenas de poções». «Centenas de substâncias de origem vegetal, animal e mineral aparecem descritas como contendo propriedades medicinais (ver cat. $\mathrm{n}^{\circ} 14$ ). Essas substâncias eram administradas pela boca como xaropes, aplicados (sic) como unguentos, emplastros, bálsamos, fomentações, introduzidos (sic) em orifícios, inalados como vapores e fumigações e inseridos como supositórios e énemas» (p. 39). Riscos da profissão de médico são patentes 
no chamado «Código» de Hammurabi (p. 38). Antigo Testamento (Israel), Hatti, Egipto, Selêucidas e Ptolemeus e Persas aqueménidas per transenam arredondam abreviadamente o tratamento (pp.41-42). Segue-se o catálogo de 21 peças ( ${ }^{\circ}$ s 2-22), oriundas de Chipre e Ásia Anterior (Síria-Palestina, Mesopotâmia, Báctria-Margiana) - numa página as bem elaboradas fotografias, na outra a descrição sucinta (material, origem, data, dimensões, $\mathrm{n}^{\circ}$ de inventário).

Maior espaço se tem de dar ao Egipto e às suas 46 peças (cat. $\mathrm{n}^{\mathrm{o}} \mathrm{s}$ 23-68), apresentadas em texto relativamente breve (pp. 68-74). «A colecção egípcia do Museu da Farmácia é um excelente acervo de uma apreciável homogeneidade, cuidadosamente reunido para reflectir uma variada produção de objectos», e ilustra «os reiterados cuidados com a beleza e o tratamento do corpo» com peças ligadas à farmacopeia, «quer a física quer a espiritual» (p. 68).

A digressão percorre as várias fases da história do Egipto faraónico. Do período pré-dinástico vêm os chamados boiões de boca negra ou os vasos com decoração geométrica pintada. A Época Arcaica (I e II dinastia) e o Império Antigo conheceram «grande produção de recipientes nas mais variadas formas e diferentes materiais». O Império Médio está presente em boiões de alabastro e outros de calcário e basalto (pelo menos dois exemplares). O Império Novo, «uma época de grande requinte e cosmopolitismo», brilha no «recipiente de anidrido formado por um macaco com colar, que segura um pequeno vaso»; entre outros objectos do mesmo período, uma estatueta funerária de Hui, «preparador de unguentos para o deus Amon», com texto hieroglífico do Livro dos Mortos. "Como exemplo das muitas imagens divinas do panteão egípcio, neste catálogo está descrita uma estatueta de bronze da deusa Ísis amamentando o seu filho Hórus (ver cat. $\mathrm{n}^{\circ} 52$ ), outra de faiança do deus Tot com cabeça de íbis, protector dos médicos e dos escribas...» (p. 69). Terceiro Intermediário, Época Baixa e Época Greco-Romana encerram a digressão (p. 70).

As derradeiras páginas (71-73) são dedicadas a temas vários: doenças e medicina no Egipto antigo, papiros médicos, literatura médica e farmacêutica (Papiro Edwin e Papiro Ebers), médicos, escolas onde se ensinava medicina, receitas e remédios, magia.

O texto encerra com um mapa do Próximo Oriente com Grécia e Creta; na parte inferior da página, um gráfico mostra o decurso das civilizações pré-clássicas, do Neolítico (c. 6500 a. C.) à Época Persa, dispondo a cronologia entre 7000 a. C. e 0 (!) d. C. O catálogo tem a mesma apresentação primorosa que topamos desde as primeiras peças 
- fotografias esmeradas, disposição primorosa, descrição sucinta (material, época, dimensões, $\mathrm{n}^{\circ}$ de inventário), tradução (mas não reprodução) do texto, quando o há. E alguns há de certa extensão, casos do da estatueta funerária de Hui (cat. $n^{\circ} 43$ ), do «escaravelho do coração» (cat. $\mathrm{n}^{\circ}$ 45) e do sarcófago (cat. $\mathrm{n}^{\circ}$ 47). Quem leu com agrado o tratamento aprofundado dos objectos noutros catálogos (Antiguidades egípcias, I; Arte egípcia, Fundação Gulbenkian), sentirá alguma secura. Mas a verdade é que o grande público não precisa de maior explanação.

«A saúde nas culturas tradicionais» começa saudavelmente com uma definição, algo prolixa é certo, mas mesmo assim definição: «Designa-se por medicina tradicional o conjunto dos conhecimentos e das práticas usadas na diagnose, na prevenção e eliminação dos sintomas físicos e/ou mentais, com base exclusivamente na experiência e na observação, e que é transmitido de geração em geração quer oralmente quer através da escrita» (pp. 125/126). «Pelo que se conhece, a religião, a magia e os tratamentos médicos eram inseparáveis uns dos outros» (p. 126). Figura central nas medicinas tradicionais eram o «curandeiro» (índios norte-americanos), o «feiticeiro» (Congo) e o «xamã» (esquimós e grupos siberianos).

O modo de lidar com os doentes e incapacitados era diferente nos diversos povos. «Entre os Cherokees e os Navajos o doente era tratado com benevolência, o estropiado e o deformado com aceitação. Nas tribos confrontadas com a fome, o suicídio dos mais velhos era aceite como um modo de retirar um fardo aos mais jovens, de quem dependia a sobrevivência de todos. Os Esqimós deixavam os seus idosos sem abrigo no gelo, quando as reservas de comida escasseavam. Em alguns grupos tradicionais, os deficientes eram mortos e comidos, para preservar a sua força vital entre a tribo» (p. 126).

Sendo a doença tida como «invasão do corpo por espíritos maléficos», não admira que os ritos mágicos fossem o remédio principal para os males do corpo. Mas não só. Citando Maurice Iwu, a Autora aponta outros modos de tratamento e cura: «Os médicos tradicionais (curandeiros) utilizam no tratamento dos doentes, para além de plantas, de minerais e de produtos de origem animal, encantamentos recitados, danças ou música, e podem também usar sacrifícios e rituais purificadores de natureza religiosa» (p. 127). Há, portanto, mistura de magia e medicina, que chegava a incluir cirurgia, tratamento de fracturas e trepanação. «Existia também um certo empirismo racional nos métodos mágicos, dado que alguns rituais religiosos eram frequentemente acompanhados por manipulações seculares de massagens, por cataplasmas e pelo saber 
das plantas medicinais...» (p. 129). «Aparentemente as sociedades tradicionais estavam submetidas às mesmas doenças que afligem as sociedades modernas, julgando pela multiplicidade de males que os xamãs tinham de enfrentar: dores de estômago, diarreias, doenças respiratórias e distúrbios menstruais. No entanto, algumas doenças foram definitivamente introduzidas mais tarde por outras civilizações» (p. 130).

Quem tiver curiosidade, pode familiarizar-se com os termos técnicos para esculturas tradicionais e agentes das práticas médicas (pp. 130-132).

O texto termina com as culturas tradicionais dispostas em manchas de planisfério (América do Norte, África Ocidental, Ásia Nordeste e Sueste), com a respectiva legenda: Esquimós, Tingit, Blackfoot, Sioux, Navajos, Apaches, Cherokees, Batak, Ioruba, Congo (Mbala, Mangbetu, Songe), Manyanga (p. 133).

Segue-se a reprodução fotográfica de 15 objectos das culturas tradicionais relacionados com a saúde, sumariamente descritos: vasos, estatuetas, almofarizes, sacos para ervas medicinais, uma garrafa para medicamento e um cachimbo cerimonial (cat. $\mathrm{n}^{\circ} \mathrm{s}$ 69-81).

$\mathrm{Na}$ «Conclusão», salienta-se a simbiose de crenças e práticas do mundo religioso e sobrenatural e prática farmacêutica e médica, recordando que «muitas das soluções encontradas ao longo dos tempos revelam-se ainda hoje válidas» (p. 151).

A «Bibliografia» (pp. 152-154) arredonda o bem elaborado volume, segundo as epígrafes do texto teórico. Para as civilizações pré-clássicas dominam os títulos em inglês e francês, ao lado de traduções portuguesas de autores estrangeiros; originais portugueses só os de Luís Manuel de Araújo e José das Candeias Sales para o Egipto. Títulos em alemão só uma ou outra entrada do Lexikon der Ägyptologie, III e IV, Wiesbaden 1980 e 1984. Podia-se acrescentar a obra de H. Grapow et alii, Grundriss der Medizin der alten Ägypter, vários volumes desde 1954; em francês E. Jonckheere, La médecine égyptienne, 3 vols., Bruxelles 1944/1958; em inglês, C. M. Sanders, The Transition from Ancient Egyptian to Greek Medicin, Lawrence 1963.

Não é difícil adivinhar quem escreveu algumas secções - Luís Manuel de Araújo «A saúde nas civilizações pré-clássicas» e Paula Basso «A saúde nas culturas tradicionais». Para as outras temos de conjecturar. Não custava nada e dava outra autoridade à Obra apor o nome do autor ou dos autores às respectivas secções.

É curioso observar como culturas tão diferentes como as pré-clássicas (as do Egipto e Mesopotâmia bem avançadas) e as tradicionais 
coincidem basicamente no modo como enfrentam a doença e procuram a cura, ou seja, recorrendo à magia e às mais variadas mezinhas. A crença não dispensava a busca racional dos remédios. Eis uma razão para não desclassificarmos apressadamente tais culturas, rotulando de superstição o que não encaixa em mentalidade positivista. E mesmo não passando de superstição, o estudo do fígado dos animais para fins terapêuticos e divinatórios levou a um apreciável conhecimento da anatomia. A este propósito, podemos lembrar a opinião de um dos grandes assiriólogos do séc. XX, Wolfram von Soden: «Aqui a medicina babilónico-assíria, por um lado, mostra-se arcaica; por outro lado, a combinação de medicina e magia antecipa de algum modo os métodos psicossomáticos modernos. As práticas mágicas avivam a vontade de melhorar do doente, sem a qual nenhuma cura se alcança. Exorcismos e orações completam o tratamento com as drogas, nas quais dificilmente se distinguiu entre efeito mágico e propriamente medicinal». ${ }^{1}$

No respeito pelos idosos diferem diametralmente as culturas préclássicas das tradicionais. Era impensável deixar morrer os idosos à fome, menos ainda abatê-los para dar de comer aos válidos. Nas civilizações pré-clássicas, os idosos eram respeitados como fontes de sabedoria; e os sábios na pujança da vida não se cansam de incutir esse respeito nas camadas mais jovens (sobretudo os Egípcios nas suas numerosas «Instruções»).

Não são muitos os reparos, em que me restrinjo obviamente às civilizações pré-clássicas. Há uma notória incongruência na apresentação da Mesopotâmia: «A Mesopotâmia é a vasta área do Médio Oriente situada entre os rios Tigre e Eufrates, no actual Iraque. Foi o berço das primeiras civilizações que ocuparam esta região - a Suméria (c. 4000-2000 a. C.), a Babilónia (2000-1350), a Assíria (1350-612) e a Caldeia (612-539)» (p. 36). Falando de civilizações, esperavam-se adjectivos que as determinassem - a suméria, a babilónica, a assíria e a caldaica. As maiúsculas e a «Caldeia» não permitem dúvidas. Trata-se de regiões e não de civilizações. Seria melhor referenciar os povos criadores de civilização na Mesopotâmia - os Sumérios e os Semitas, estes nos seus principais ramos, Babilónios e Assírios. Caldeia não é mais que a região do Sul da Mesopotâmia durante o período babilónico recente. As datas são naturalmente aproximadas. Mesmo assim, convinha fixar 3500 a. C. para o início da presença suméria na Mesopotâmia e não terminar Babilónia em 1350. A dinastia cassita

${ }^{1}$ Einführung in die Altorientalistik, Wissenschafliche Buchgesellschaf, Darmstadt 1985, p. 155. 
aguentou-se em Babilónia frente ao Império Médio assírio até c. 1235 a. C. e a II dinastia de Isin até 1046 a. C. Até no apogeu do Império Neoassírio (912-631/629 a. C.), Babilónia continuou com a sua identidade política (desde Tiglat-Pileser III, em745, como Reino Unido) e sobretudo cultural, para grande inveja dos Assírios.

No gráfico das épocas (p. 43) escapou um inexistente ano 0 (desafiando a matemática, ao ano 1 a. C. segue-se o ano 1 d. C.). As civilizações pré-clássicas da Ásia, se não terminaram com a conquista de Alexandre Magno a partir de 333 a. C., perderam a sua autonomia. Não assim a civilização egípcia, que se manteve mesmo sob os conquistadores greco-romanos. Na sucessão das épocas históricas, haveria lugar para o Calcolítico (c. 4500-3000 a. C.) entre Neolítico e Época Suméria, em que se inclui Época Pré-dinástica no Egipto (c. 3800-3330/3200 a. C.).

É verdade que do impropriamente chamado (falta-lhe um conceito e uma organização global da matéria jurídica) «código» de Hammurabi se vêem os «riscos» da profissão de médico em Babilónia (p. 39); de facto, incúria ou negligência grave no tratamento de um cidadão de pleno direito (awilum) levava à pena de morte ( $§ 218)$. Mas o legislador também reconhecia os direitos, estabelecendo os honorários dos clínicos, os quais ocupam mais espaço do que as penas ( $\S \S 215-217 ; 221-223$ ).

Reparo mais formal toca a grafia de topónimos, antropónimos e teónimos das línguas semíticas e do hitita. É conhecida a insistência de Luís Manuel de Araújo numa forma pretensamente aportuguesada de tais termos. Recusando liminarmente a transliteração da sibilante $\check{s}$ das línguas semíticas alfabéticas pelo grafema sh à inglesa, escreve sempre, aqui como noutros lugares, Kadech, Kanech, Karkemich, Hattucha, Kich, Echnunna (mapa, p. 40). Com a maior simpatia pelo esforço de conservação da língua pátria (também a mim me repugna visceralmente o abastardamento do idioma e da sua ortografia), há que reconhecer que tal grafia é de veras aberrante na tradição ortográfica portuguesa. Em topónimos de origem bíblica, $c h$ translitera em latim os hebraicos כ כ e $\Pi$ (esporadicamente $\mathrm{p}$ ) e o grego $\chi$, donde passou ao português antigo com o valor de $k$. Daí os antropónimos Christo, Zacharias, «Issachar» ${ }^{2}$, «Melchisedech» ${ }^{3}$ «Machabeos» ${ }^{4}$, «Nabuchdonosor». ${ }^{5}$ Em nomes de

${ }^{2}$ Ibid., LXXIX, 449.

${ }^{3}$ Ibid., XXII, 114; LXXV, 428

${ }^{4}$ Ibid., XC, 520.

${ }^{5}$ D. António da Costa, Tratado da Viagem que fez da India Oriental à Europa, manuscrito CXV / 1-5, da Biblioteca Pública e Arquivo Distrital de Évora, fol. 73. 
rios, Mestre Afonso, um cirurgião muito atento à geografia, tanto escreve rio «Chúr» ${ }^{6}$ como «Cúr». ${ }^{7}$

Se queremos tradição ortográfica portuguesa para os topónimos da Ásia Anterior nada melhor que ler os viajantes de Quinhentos e Seiscentos que por lá passaram. Assim, Frei Pantaleão de Aveiro escreve «Sichar ou Sichen» ${ }^{8}$ (Siquém, na Palestina central) e «Narchelb (Na'arkelb), rio do Cão» ${ }^{9}$, no actual Líbano. António Tenreiro passou por «Antiochia» ${ }^{10} \mathrm{e}$ admirou com razão os «moimentos» de «Balbeche» ${ }^{11}$ (Ba'albek). Considero obviamente ultrapassada essa forma de transliteração. Mesmo assim, dificilmente alguém lerá hoje Kadech, Kanech, Lagach de outro modo que Kadec, Kanec, Lagac, se não Kadekh, Kanekh, Lagakh.

Para o equivalente português ao $\check{s}$ os viajantes escritores não acharam melhor que $x$, não $c h$. Na Pérsia tocaram Xirás/Xiras ${ }^{12} \mathrm{e}$ Caixão ${ }^{13}$ (Kashan); na Síria, estiveram em Damasco, «que em sua linguagem elles chamão o Xame» ${ }^{14}$, «polos mouros chamado o Xame» ${ }^{15}$ (es-Sham); no actual Iraque, Tenreiro esteve em Xefeta, «em o deserto» ${ }^{16}$ e Mexeta de $\mathrm{Ali}^{17}$; só ele chegou ao Egipto, onde tocou «Raxite» ${ }^{18}$ (Rashid, Roseta); na Turquia, só Mestre Afonso esteve em Múx. ${ }^{19}$ Nos

${ }^{6}$ «Ytinerario de Mestre Afonso», in António Baião, Itinerários da Índia a Portugal por terra, Coimbra 1925, p. 185.

${ }^{7}$ Ibid., 222.

${ }^{8}$ Itinerario da Terra Sancta, Coimbra ${ }^{7} 1927$, LXXIX, 447; p. 453: Sichem.

${ }^{9}$ Ibid., XC, 522.

10 «Itinerário de António Tenrreyro», LI, in António Baião, Itinerários da Índia, 99.

${ }^{11}$ Ibid., XXXII, 67.

${ }^{12}$ Ibid., VI, 16; VII, 16, 20, entre outros lugares; Xiras para Mestre Afonso ( «Ytinerario», 170) e Orta Rebelo (Relação Da Jornada que fez Nicolao Dorta Rabello, editado por Joaquim Veríssimo Serrão, Un voyageur portugais en Perse au début du $X V I{ }^{e}$ siècle: Nicolau de Orta Rebelo, Lisbonne 1972, pp. 116, 122, 128).

13 «Itinerário de António Tenrreyro», X, 23; «Ytinerario de Mestre Afonso», 164.

14 «Itinerário de António Tenrreyro», XXXII, 67.

${ }^{15}$ Ibid., 68.

${ }^{16}$ Ibid., LIV, 104.

${ }^{17}$ Ibid., LV, 105.

${ }^{18}$ Ibid., XLV, 92; XLVI, 92.

19 «Ytinerario de Mestre Afonso», 219. 
nomes comuns a transliteração não varia: sempre $x$ como em xisto: «Xá» da Pérsia, «xatamás», «baxá/paxá», vento «xamal», seita religiosa dos «xamsi», adoradores do Sol, pois «xem em lingua arabia quer dizer sol». ${ }^{20}$ Daqui se tiraria a melhor forma portuguesa do deus mesopotâmico do Sol: Xamax, nunca «Chamach». Mas não vale a pena terçar armas por indumentária ortográfica lusitana, quando a generalidade dos autores escrevendo em francês ${ }^{21}$, italiano ${ }^{22}$ e espanhol ${ }^{23}$ (línguas românicas como o português), se não opta pelo rigoroso $\check{s}$, renuncia à praxe ortográfica da sua língua e adopta o sh inglês em Lagash, Kish, Kadesh, Karduniash, Karkemish, Hattusha, Shamash, Gilgamesh e semelhantes. ${ }^{24}$

Já se encontraria porventura melhor vernáculo para «Hórus Criança» (p. 70 e cat. $\mathrm{n}^{\circ} \mathrm{s} 49$ e 56), a quem Ísis dá o peito num conjunto escultórico (cat. $\mathrm{n}^{\circ}$ 52). Na religião egípcia da Época Greco-Romana, a devoção à mãe divina Ísis não só ultrapassou todos os outros cultos no Egipto, mas estendeu-se ao império romano. Ísis amamentando Hórus é o protótipo directo da Madonna lactans da iconografia paleocristã e medieval. $\mathrm{O}$ «Menino Jesus» sucedeu iconograficamente ao «Menino Hórus».

Lapsos de conteúdo e de forma não tiram o prazer da leitura dos textos introdutórios e da fruição das belas imagens do catálogo.

\section{${ }^{20}$ Ibid., 248.}

${ }^{21}$ A título de exemplo, André Caquot-Maurice Sznycer-Andrée Herdner, Textes ougaritiques, I. Mythes et légendes (LAPO 7), Paris 1974; Raymond Jaques Tournay, O. P.-Aaron Shaffer, L'épopée de Gilgamesh (LAPO 15), Paris 1994.

${ }_{22}$ Mario Liverani, Antico Oriente. Storia, società, economia, Roma/Bari 1988; Idem, Le lettere di el-Amarna, I-II, Brescia 1998.

${ }^{23}$ Josep Padró, Historia del Egipto faraónico, Madrid 1996.

${ }^{24}$ Até o malogrado assiriólogo brasileiro Emanuel Bouzon condescendeu com o hábito corrente na primeira edição de As Leis de Eshnunna, Petrópolis 1981; na segunda edição, converte o título em Uma coleção de direito babilônico pré-hammurbiano. Leis do reino de Ešnunna, Petrópolis 2001. No corpo da obra e em outros escritos, por exemplo, O Código de Hammurabi, Petrópolis ${ }^{4} 1987$, usa coerentemente š tanto nas introduções e comentários como na versão a partir do original acádico. 